\title{
Lise Öğrencilerinin Olumsuz Değerlendirilme Korkularının Akademik Başarıya İlişkin Bilişsel Çarpıtmalar Bağlamında İncelenmesi
}

\author{
Mustafa Pamuk a, b
}

\section{Özet}

$\mathrm{Bu}$ araştırmanın amacı lise öğrencilerinin akademik ortamlarda olumsuz değerlendirilme korkularının akademik başarıya ilişkin bilişsel hatalar bağlamında incelenmesidir. Araştırmanın katılımcıları Konya'da farklı lise türlerinde okuyan toplamda 915 öğrenciden oluşmaktadır. Elde edilen verilerin analizinde pearson korelasyon katsayısı ve aşamalı regresyon analizi kullanılmıştır. Elde edilen sonuçlara göre lise öğrencilerinin akademik ortamlarda olumsuz değerlendirilme korkularının sırasıyla felaketleştirme, benlik değeri, dışa atıf ve mükemmeliyetçilik değişkenleri tarafından istatistiksel olarak anlamlı şekilde yordandığı bulunmuştur. Elde edilen bulgular doğrultusunda tartışma yapılmış ve bazı önerilerde bulunulmuştur.
Anahtar Kelimeler

Olumsuz değerlendirilme korkusu

Felaketleştirme

Benlik değeri

Dişa atıf

Mükemmeliyetçilik

Makale Hakkında

Geliş Tarihi: 15.01.2020

Kabul Tarihi: 26.03.2021

Doi: $10.18026 /$ cbayarsos.675058

\section{Investigation of High School Students' Fears of Negative Evaluation in the Context of Cognitive Distortions Regarding Academic}

\begin{abstract}
The aim of this study is to investigate the fears of negative evaluation of high school students in academic settings in the context of cognitive errors related to academic achievement. The participants of the research consisted of 915 students from different high school types in Konya. Pearson correlation coefficient and stepwise regression analysis were used in the analysis of the obtained data. According to the results, it was found that high school students' fear of negative evaluation in academic settings was statistically significant predicted by catastrophizing, self-value, outer attribution and perfectionism variables, respectively. In the light of the findings, some discussions were made and some suggestions were made.
\end{abstract}

Keywords

Fear of negative evaluation

Catastrophizing

Self-value

Outer attribution

Perfectionism

About Article

Received: 15.01 .2020

Accepted: 26.03.2021

Doi: 10.18026/cbayarsos. 675058

a İletişim Yazarı: mustafa.pamuk@selcuk.edu.tr

b Dr. Öğr. Üyesi, Selçuk Üniversitesi Eğitim Fakültesi Eğitim Bilimleri Bölümü Rehberlik ve Psikolojik Danışmanlık ABD, ORCID: 0000-0001-8367- 


\section{Giriş}

Sosyal bir canlı olan insanoğlu yaşamında birçok ortamda diğer bireylerle etkileşimde bulunmaktadır. Bu etkileşim esnasında bazı bireyler başkaları tarafından olumsuz değerlendirilme korkusu yaşayabilmektedir. Reichenberger, Smyth ve Blechert'e (2018) göre sosyal etkileşimler kaçınılmaz olarak tekrarlanan değerlendirmelerle devam etmektedir ve bazı bireyler bu duruma karşı daha hassas olabilmektedirler. Leary (1983) bu olumsuz değerlendirilme korkusunu bir kişinin başkaları tarafından farklı veya düşmanca değerlendirilebilme kaygısı olarak tanımlamıştır.

Bilişsel-davranışsal modeller, olumsuz değerlendirme korkusunun sosyal kayg1 bozukluğunun temel özelliği olduğunu öne sürmektedir (Weeks, Heimberg ve Rodebaugh, 2008). Yüksek düzeyde olumsuz değerlendirilme korkusuna sahip kişiler, sosyal onay kaybından korkar ve başkaları tarafından olumlu değerlendirmeleri korumak veya elde etmek için güçlü bir istek duymaktadır (Utschig, Presnell, Madeley ve Smits, 2010). Olumsuz değerlendirilme korkusuna ilişkin alanyazın incelendiğinde, bu değişkenin bulimik semptomlarla (Utschig vd., 2010), sosyal kaygiyla (Carleton, Collimore ve Asmundson, 2007; Cheng, Zhang ve Ding, 2015; Pitarch, 2010), yalnızlıkla (Duke, Krishnan, Faith ve Storch, 2006), depresyonla (Duke vd., 2006), düşük öz saygiyla (Cheng vd., 2015; Kocovski ve Endler, 2000), utangaçlıkla (Koydemir-Özden ve Demir, 2009), akademik stresle (Nonterah vd., 2015), durumluluk-sürekli kaygıyla (Nonterah vd., 2015), akademik risk almayla (Çetin, İlhan ve Yılmaz, 2014) ilişkili olduğu görülmektedir.

Olumsuz değerlendirilme korkusuna ilişkin olarak yapılan çalışmalar dikkate alındığında, bu değişkenin farklı gruplarda çalışıldığı görülmektedir. Olumsuz değerlendirilme korkusunun kamu çalışanlarıyla (Kanbur, 2018), spor merkezlerine giden bireylerle (Köse, Bayköse, Turan ve Lapa, 2016), tekvandocularla (Atasoy, Karabulut ve Var, 2018), yetişkin kekeme bireylerle (Brundage, Winters ve Beilby, 2017), işitime engelli yetişkinlerle (Williams, Falkum ve Martinsen, 2015), uyuşturucu bağımlılarıyla (Talhat ve Aslam, 2012), obeziteli bireylerle (Khan ve Naqvi, 2016) çalışıldığı görülmektedir. Diğer bir çalışılan grup ise akademik ortamlarda yer alan öğrencilerdir (Çelik ve Odacı, 2015; Çetin, Doğan ve Sapmaz, 2010; Pitarch, 2010). Öğrencilerin günlük yaşamların bir parçası olan okul, sınıf gibi akademik ortamlarda öğrenciler birçok açıdan değerlendirmeye tabi tutulmaktadırlar. Downing, Cooper, Cala, Gin ve Brownell (2020) yapmış oldukları çalışmada, aktif öğrenmede öğrenci kaygısının altında yatan birincil yapının olumsuz değerlendirme korkusu olduğunu bulmuşlardır. Alkan (2015) akademik ortamlarda olumsuz değerlendirilme korkusunu, öğrencilerin okulda öğretmenleri ve arkadaşları, evde ise ebeveynleri tarafından akademik başarılarının olumsuz değerlendirilmesinden korkmaları olarak tanımlamıştır.

Araştırmada ele alınan diğer bir değişken ise akademik başarıya ilişkin bilişsel çarpıtmalardır. Bilişsel çarpıtmalar, depresyona karşı savunmasızlı̆̆ı arttırdığı iddia edilen olumsuz düşünme yanlılıklarıdır (Dozois ve Beck, 2008). Pereira, Barros ve Mendonça'ya (2012) göre bilişsel çarpıtmalar, gerçeğe dayanmayan olayların yorumlanmasında olumsuz bir önyargı ile karakterize edilir. Hatta bu yorumlamalara ilişkin birçok gerçekçi temel olmasına rağmen, bu bilişlerin tekrarlayıcı, kendine zarar veren ve aşırı olumsuzluklar içeren yapısından dolayı, bu durum bireylerin iyi oluşlarına ve uyumlarına olumsuz etki etmektedir. Knights ve Kennedy'e (2007) göre ise işlevsel olmayan kişilik özellikleri bu bireylerin öğrenme süreçleri, akademik 
motivasyonları, notları ve derse katılımları üzerinde olumsuz etkiye sahiptir. Duran, Karadaş ve Kaynak (2017) yapmış oldukları çalışmada üniversite öğrencilerinin kendilerine yönelik otomatik düşüncelerinin akademik başarıyla negatif yönlü bir ilişkiye sahip olduğunu bulmuşlardır. Çelik ve Odacı (2015) ise akademik erteleme davranışı ile olumsuz değerlendirilme korkusu ve akılcı olmayan inançlar arasında pozitif yönlü anlamlı ilişki bulmuşlardır.

İlgili alanyazın dikkate alındığında, temelinde değerlendirme olan akademik ortamlarda bulunan öğrencilerin, bu ortamlarda yaşadıkları akademik bağlamda olumsuz değerlendirilme korkularını, akademik başarıya ilişkin bilişsel çarpıtmalarla inceleyen bir çalışmaya rastlanılmamıştır. Öğrencilerle yapılan çalışmalarda genel olarak olumsuz değerlendirilme korkusu değişkeninin kullanıldı̆̆ Argon, 2014; Özgüngör, 2006); ancak öğrencilerle bulundukları ortam olan akademik ortamlarda yaşadıkları olumsuz değerlendirilme korkusunun doğrudan ölçen yeni çalışmalara ihtiyaç duyulmaya başlanmıştır (Alkan, 2015; İlhan ve Güler, 2018). Bu araştırmanın ilgili alanyazına katkı sağlayacağı; aynı zamanda ilerde akademik ortamlarda olumsuz değerlendirilme korkusu üzerine yapılacak deneysel çalışmalara teorik alt yapı da sağlayabileceği söylenebilir. Bu bağlamda bu araştırmanın amacı liseye devam eden öğrencilerin akademik başarıya ilişkin bilişsel hatalarının akademik ortamlarda olumsuz değerlendirilme korkusu üzerindeki rolünün incelenmesidir. Bu amaç doğrultusunda şu sorulara yanıt aranmıştır:

1- Lise öğrencilerinin akademik ortamlarda olumsuz değerlendirilme korkuları ile akademik başarıya ilişkin bilişsel çarpıtmalar arasında anlamlı ilişki var mıdır?

2- Lise öğrencilerinin akademik ortamlarda olumsuz değerlendirilme korkularını akademik başarıya ilişkin bilişsel çarpıtmalar anlamlı düzeyde yordamakta mıdır?

\section{Yöntem}

Bu bölümde araştırmanın modeli, katılımcları, kullanılacak veri toplama araçları ve sürece ilişkin bilgiler yer almaktadır.

\section{Araştırma Modeli}

$\mathrm{Bu}$ araştırmada ilişkisel tarama modellerinden yordayı ı korelasyonel araştırma deseni kullanılmıştır. Yordayıcı korelasyonel araştırmalar bir ya da daha fazla bağımsız değişkene bağlı olarak bağımlı değişkende meydana gelen değişimleri açıklamak amacıyla gerçekleştirilmektedir (Büyüköztürk, Kılıç Çakmak, Akgün, Karadeniz ve Demirel, 2012). Bu çalışmada da ortaöğretim öğrencilerinin akademik ortamlarda olumsuz değerlendirilme korkularında akademik başarıya ilişkin bilişsel çarpıtmalarının rolü incelenmiştir.

\section{Araştırmanın Örneklemi}

Bu çalışmanın katılımcılarını 2019-2020 Eğitim-Öğretim güz döneminde Konya' da farklı türde ortaöğretim kurumlarında ortaöğretime devam eden 246'sı Anadolu lisesi, 184'ü fen lisesi, 241'i imam hatip lisesi ve 244'ü de mesleki ve teknik lise olmak üzere toplamda 915 öğrenci oluşturmaktadır. Katılımcların 404'ü $(\% 44,1)$ erkek, 511'i $(\% 55,9)$ ise kızlardan oluşmaktadır. 


\section{Veri Toplama Araçları}

Olumsuz Değerlendirilme Korkusu-Öğrenci Formu (ODK-ÖF): ODK-ÖF ortaöğretime devam eden öğrencilerin akademik ortamlarda yaşadıkları olumsuz değerlendirilme korkularını ölçmek amacıyla İlhan ve Güler (2018) tarafından geliştirilmiştir. ODKÖ-ÖF'ye ilişkin yapılan Rasch analizi sonuçları, 16 maddeden oluşan tek boyutlu modelde öğrenciler ve maddelerin yüksek güvenirlikte birbirinden ayırt edildiğini, ölçekte kullanılan beşli derecelendirmenin etkin bir biçimde çalıştığını, uyum istatistiklerinin kabul edilebilir sınırlar içerisinde kaldığını ve gözlenen ile beklenen test karakteristik eğrilerinin büyük ölçüde örtüştügünü göstermiştir. Çok yüzeyli Rasch analizine göre, öğrencilerin sinıf ortamında öğretmenleri ya da arkadaşları tarafından olumsuz değerlendirileceklerine dair yaşadıkları

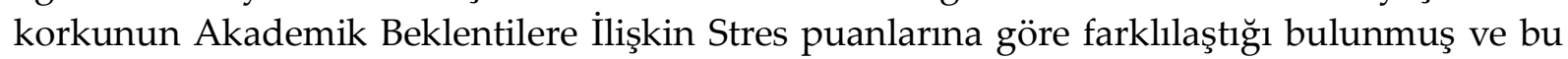
bulgunun ODKÖ-ÖF'nin ölçüt geçerliğine yönelik bir kanıt olarak yorumlanmıştır. Bu araştırma kapsamında Cronbach Alpha iç tutarlık katsayısı .90 olarak bulunmuştur.

Akademik Başarıya İlişkin Bilişsel Çarpıtmalar Ölçeği (ABİBHÖ) : ABİBHÖ ortaöğretime devam eden öğrencilerin akademik başarıya ilişkin bilişsel çarpıtmalarını ölçmek amacıyla Kaya (2018) tarafından geliştirilmiştir. Yapılan açımlayıcı faktör analizi sonucunda toplam varyansın \%50, 87'sini açklayan dört faktörlü (felaketleştirme, benlik değeri, dışa atıf ve mükemmelleştirme), 25 maddeli bir form elde edilmiştir. Elde edilen dört faktörlü yapının model uyum değerlerini incelemek amaciyla farklı bir grupla doğrulayıcı faktör analizi yapılmış ve elde edilen sonuçlar $\left(\mathrm{X}^{2} / \mathrm{sd}=2,29\right.$; $\left.\mathrm{RMSEA}=.08 ; \mathrm{CFI}=.95 ; \mathrm{NNFI}=.95 ; \mathrm{SRMR}=.08\right)$ ölçeğin model veri uyumunun iyi düzeyde olduğunu göstermiştir. Ölçeğe ilişkin güvenirlik analizleri sonucunda Cronbach's Alfa iç tutarlılık kat sayısı felaketleştirme alt boyutu için .82, benlik değeri alt boyutu için .84 , dişa atıf alt boyutu için .80 ve mükemmelleştirme alt boyutu için ise .78 olarak bulunmuştur. Bu araştırma kapsamında Cronbach Alpha iç tutarlık katsayısı felaketleştirme alt boyutu için .88 , benlik değeri alt boyutu için .87 , dışa atıf alt boyutu için .81 ve mükemmelleştirme alt boyutu için ise .83 olarak bulunmuştur.

\section{Verilerin Toplanması ve Analizi}

Araştırma kapsamında öncelikli olarak araştırma kapsamında kullanılan ölçeklerin yazarlarından kullanım izni alınmıştır. Akabinde Milli Eğitim Bakanlı̆̆ı'nın www.ayse.meb.gov.tr adresi üzerinden Konya merkezde yer alan bazı liselerde uygulama izni için kayıt yapılmıştır. Bu kayıt çıktısı ve uygulamada kullanılan ölçeklerin de içinde olduğu araştırma önerisiyle beraber rektörlük aracılığıyla Konya Milli Eğitim Müdürlüğü'ne (MEM) başvuru yapılmıştır. Konya MEM'den izin alındıktan sonra izin yazısıyla izin alınan okullara gidilmiş ve rehberlik servislerinin desteği de alınarak gönüllü öğrencilere uygulama yapılmıştır. Elde edilen verilerin SPSS paket programına girildikten sonra, basıklık ve çarpıklık katsayısı, Cronbach Alpha güvenirlik katsayısı, Pearson korelasyon katsayısı ve aşamalı regresyon hesaplamaları yapılmıştır. Regresyon analizinin başlangıcında VIF değerleri, Tolerans değerleri (TD) ve bağımsız değişkenler arasındaki korelasyon katsayıları hesaplanmıştır. Regresyon modeli için VIF değerlerinin 1.144-1.703, Tolerans değerlerinin ise 0.587-0.874 arasında olduğu ve Tablo 1'de görüldüğü üzere bağımsız değişkenler arasındaki korelasyonlar da 0.30-0.64 arasında değişmektedir. TD değerinin 0.2' den büyük olması, VIF değerinin ise 10' dan küçük olması (Field, 2005), bağımsız değişkenler (yordayıcılar) arasındaki korelasyonun .80'in altında olması (Büyüköztürk, 2010; Field, 2005) gerekmektedir. Regresyon 
analizi öncesi gerekli değerleri aldıkları ve çoklu bağlantı problemiyle karşılaşılmadığ görülmüştür.

\section{Bulgular}

Bu kısımda araştırmadan elde edilen verilere ilişkin basıklık ve çarpıklık değerleri, Cronbach Alpha iç tutarlılık katsayısı, Pearson korelasyon katsayısı ve aşamalı regresyon analizleri yer almaktadır.

Tablo 1. Olumsuz değerlendirilme korkusu-öğrenci formu ve akademik başarıya ilişkin bilişsel hatalar ölçeği'nin alt boyutlarına ilişkin Pearson korelasyon, basıklık, çarpıklık ve Cronbach Alpha katsayıları

\begin{tabular}{lcccccccc}
\hline & 1.ODK-ÖF & 2.Fe & 3.BD & 4.DA & 5.Mü & Basıklık & Çarpıklık & $\begin{array}{c}\text { Cronbach } \\
\text { Alpha }\end{array}$ \\
\hline 1.ODK-ÖF & 1 & & & & & -.340 & .165 & .90 \\
2.Fe & $.46^{*}$ & 1 & & & & -.606 & .003 & .88 \\
3.BD & $.42^{*}$ & $.45^{*}$ & 1 & & & .735 & 1,059 & .87 \\
4.DA & $.37^{*}$ & $.36^{*}$ & $.64^{*}$ & 1 & & .728 & .968 & .81 \\
5.Mü & $.37^{*}$ & $.59^{*}$ & $.41^{*}$ & $.30^{*}$ & 1 & -.685 & .064 & .83 \\
\hline
\end{tabular}

${ }^{*} \mathrm{p}<.01$, ODK-ÖF : Olumsuz Değerlendirilme Korkusu-Öğrenci Formu, Fe : Felaketleştirme, BD : Benlik Değeri, DA: Dışa Atıf, Mü : Mükemmeliyetçilik

Tablo 1'de görüldüğü gibi, ODK-ÖF ile sırasıyla Fe, BD, DA ve Mü arasında pozitif yönlü orta düzeyde ilişki olduğu bulunmuştur ( $r=0,46 ; r=0,42 ; r=0,37 ; r=37)$. Ayrıca Fe'nin, sırasıyla BD, DA ve Mü ile pozitif yönde ilişkili olduğu bulunmuştur ( $r=0,45 ; r=0,36 ; r=0,59)$. BD ise sırasıyla DA ve Mü pozitif yönde ilişkili olduğu bulunmuştur $(r=0,64 ; r=0,41)$. Son olarak ise DA ve Mü arasında da pozitif yönlü ilişki olduğu bulunmuştur $(r=0,30)$.

Tablo 2. Lise öğrencilerinin olumsuz değerlendirilme korkusunun yordanmasına ilişkin aşamalı regresyon analizi sonuçları

\begin{tabular}{cccccccccc}
\hline Model & Değişken & $\mathbf{B}$ & Standart Hata & $\boldsymbol{\beta}$ & $\mathbf{t}$ & $\mathbf{p}$ & $\mathbf{R}$ & $\mathbf{R}^{2}$ & $\mathbf{F}$ \\
\hline Model 1 & Sabit & 22.382 & 1.213 & & 18.455 & .000 & .458 & .210 & $242.886^{*}$ \\
& Fe & .760 & .049 & .458 & 15.585 & .000 & & & \\
\hline \multirow{3}{*}{ Model 2 } & Sabit & 19,814 & 1,206 & & 16.428 & .000 & & & \\
& Fe & .558 & .053 & .337 & 10.613 & .000 & .518 & .268 & $167.241^{*}$ \\
& BD & .642 & .075 & .270 & 8.518 & .000 & & & \\
\hline \multirow{4}{*}{ Model 3 } & Sabit & 18.481 & 1,255 & & 14.729 & .000 & & & \\
& Fe & .540 & .053 & .326 & 10.280 & .000 & & & \\
& BD & .454 & .091 & .191 & 4.973 & .000 & .528 & .279 & $117.227^{*}$ \\
& DA & .335 & .093 & .132 & 3.585 & .000 & & & \\
\hline \multirow{5}{*}{ Model 4 } & Sabit & 17.484 & 1.298 & & 13.474 & .000 & & & \\
& Fe & .455 & .060 & .274 & 7.567 & .000 & & & \\
& BD & .410 & .092 & .173 & 4.444 & .000 & .534 & .285 & $90.652^{*}$ \\
& DA & .334 & .093 & .131 & 3.591 & .000 & & & \\
\hline${ }_{*}^{*}<05$ & Mü & .254 & .089 & .101 & 2.857 & .000 & & & \\
& & & & & & & & &
\end{tabular}

Akademik başarıya ilişkin bilişsel hatalar ölçeğinin alt boyutları olan Fe, BD, DA ve Mü değişkenlerinin lise öğrencilerinin akademik ortamlarda olumsuz değerlendirilme korkularını açıklama gücünü ortaya koymak amacıyla aşamalı çoklu regresyon analizi yapılmıştır. Analiz sonucunda dört farklı regresyon modeli ortaya çıkmıştır. Tablo 2 incelendiğinde, Fe'nin 
akademik ortamlarda olumsuz değerlendirilme korkusuna ilişkin varyansın yaklaşık olarak \%21'ini açıkladığı görülmektedir. Fe değişkenine BD değişkeni eklendiğinde açılanma oranının yaklaşık olarak \%27'ye yükseldiği görülmektedir. Fe, BD değişkenlerine DA değişkeni eklendiğinde açıklanma oranının yaklaşık olarak \%28'e yükseldiği görülmektedir. Son olarak Fe, BD, DA değişkenlerine Mü değişkeni eklendiğinde açıklanma oranının yaklaşık olarak \%29'a yükseldiği görülmektedir. Standardize edilmiş regresyon katsayıları $(\beta)$ incelendiğinde $\mathrm{Fe}, \mathrm{BD}$, DA ve Mü değişkenlerinin akademik ortamlarda olumsuz değerlendirilme korkusu değişkenini pozitif yönde yordadığı sonucuna ulaşılmıştır.

\section{Tartışma, Sonuç ve Öneriler}

Liseli öğrencilerin akademik ortamlarda olumsuz değerlendirilme korkularında akademik başarıya ilişkin bilişsel çarpıtmaların rolünün incelendiği bu araştırmada, sırasıyla felaketleştirme, benlik değeri, dışa atıf ve mükemmeliyetçilik alt boyutlarının öğrencilerin akademik ortamlarda olumsuz değerlendirilme korkularını istatistiksel olarak anlamlı düzeyde yordadıkları bulunmuştur. Standardize edilmiş $\beta$ değerleri dikkate alındığında, akademik başarıya ilişkin bilişsel hatalar arttıkça öğrencilerin akademik ortamlarda yaşadıkları olumsuz değerlendirilme korkularının arttığı söylenebilir. Alanyazında bilişsel hataların kaygıyla ilişkili olduğunu (Kuru vd., 2018; Pererira, Barros ve Mendonça, 2012) ve kaygının yordanmasında bilişsel hataların rolü olduğunu gösteren araştırmalara rastlanmaktadır (Cook, Meyer ve Knowles, 2019; Weems, Berman, Silverman ve Saavedraa, 2001). Bu araştırmada da akademik ortamlarda, sosyal kaygının çekirdeğinde yer alan bir kavram olan olumsuz değerlendirilme korkusunun (Weeks vd., 2008) yordanmasında, yukarıda bahsedilen alanyazın sonuçlarıyla benzer şekilde, akademik başarıya ilişkin bilişsel çarpitmaların rolünün olduğu bulunmuştur. Bu araştırmadan elde edilen sonuçlar, bilişsel kuramların temelinde yer alan, kaygı gibi duygusal rahatsızlıların hatalı veya olumsuz düşünmeden kaynakladığı düşüncesini desteklemektedir (Bridges ve Harnish, 2010).

Akademik ortamlarda olumsuz değerlendirilme korkusuna ilişkin varyansı en çok açıklayan değişken felaketleştirme olmuştur. Lise öğrencilerinin akademik başarıya ilişkin felaketleştirme eğilimleri arttıça akademik ortamlarda olumsuz değerlendirilme korkularının da arttı̆̆1 söylenebilir. Deffenbacher, Zwemer, Whisman, Hill ve Sloan (1986) yapmış oldukları çalışmada felaketleştirmeyle olumsuz değerlendirilme korkuları arasında pozitif yönlü anlamlı bir ilişki bulmuşlardır. Bilişsel modele göre felaketleştirme, olası en kötü sonuçlara odaklanan sürekli bir önyargı kaynağı olarak hizmet veren hatalı bir şemadır (Chan, Chan ve Kwok, 2015). Çarkıt (2016) yapmış olduğu çalışmada öğrencilerin hata yapma endişeleri ve yaptıklarından emin olamama davranışlarının önemli bir yordayıcısının bilişsel hatalardan olan felaketleştirmenin olduğunu bulmuştur. Akademik bağlamda alanyazın ve bu araştırmanın sonuçları da dikkate alınarak bu durum değerlendirildiğinde, lise öğrencilerinin sınıf gibi akademik ortamlarda derse katılım konusunda veya anlayamadığ noktaları sorma konusunda öğretmeni veya arkadaşları karşısında gülünç duruma düşme, rezil olma, hata yapma endişesi gibi düşünme biçimleri öğrencilerin akademik ortamlarda olumsuz değerlendirilme korkularını arttırabilir.

Akademik ortamlarda olumsuz değerlendirilme korkusunu yordayan değişkenlerden biri de benlik değeri olmuştur. Alanyazında doğrudan akademik ortamlarda olumsuz değerlendirilme korkusuyla akademik başarıya ilişkin bilişsel çarpıtmalardan olan benlik 
değerini ele alan herhangi bir çalışmaya rastlanılmamış fakat öğrencilerin benlik saygısının olumsuz değerlendirilme korkusuyla ilişkili olduğunu gösteren çalışmalara rastlanılmıştır (Çelik ve Atilla, 2019; Khanam ve Moghal, 2012; Koydemir-Özden ve Demir, 2009). Bu çalışmaların sonuçları dikkate alındığında, öğrencilerin benlik saygısı düştükçe olumsuz değerlendirilme korkularının arttığı söylenebilir. Öğrencilerin akademik ortamlarda kendilerini yetersiz görmeleri, yeteneklerinden şüphe etmeleri öğrencilerin akademik ortamlarda olumsuz değerlendirilme korkularını tetikleyebilir (Çelik ve Atilla, 2019). Akademik başarıya ilişkin bilişsel çarpıtmalardan olan benlik değerinde birey, başarıyı benlik değeriyle eş değer görmektedir (Kaya, 2018). Bu çalışmada elde edilen sonuç dikkate alındığında, öğrencilerin başarısız olma korkuları veya sınıfta öğretmenlerinin, arkadaşlarının gözünde başarısız öğrenci profili çizme korkuları, öğrencilerin akademik ortamlarda olumsuz değerlendirilme korkularının artmasına neden olabilir.

Akademik ortamlarda olumsuz değerlendirilme korkusunu yordayan değişkenlerden biri de dışa atıf olmuştur. Dışa atıf, Kaya (2018) tarafından kişinin başarı ve başarısızlığı kendi dışındaki faktörlere atfetmesi olarak tanımlanmıştır. Kızgın ve Dalgın'a (2012) göre bir öğrenci derslerden başarılı olmak adına yeterince gayret gösterdiği halde başarısız olursa, bu durumu sınavların zorluğu gibi dışsal değişkenlere ya da dersi geçme konusunda yetenek eksikliği gibi içsel bir değişkene veya başarılı olursa sınavın kolay olmasına bağlayabilir. Bıçak (2019) üniversitede İngilizce hazırlık sınıfında tekrar yapan öğrencilerle yapmış olduğu çalışmasında öğrencilerin başarısızlıkları için dışsal nedenlerde daha çok okulla ilgili olmak üzere sınavla, aile ve sosyal hayatla ilgili sebeplere atıflar yaptıklarını bulmuştur. Bahadır (2020) üniversite öğrencileriyle başarı ve başarısızlık nedenleri üzerine yapmış olduğu çalışmada, öğrencilerin başarısızlıklarında ailelerinin destek olmaması, ailelerinden uzak olmaları, öğretim üyelerinin kaliteli ders vermemesi gibi sebeplere vurgu yaptıkları belirlenmiştir. Lise öğrencilerinin akademik ortamlarda olumsuz değerlendirilme korkuları arttıkça, bu korkudan kaçınmak adına nedensel atfetmeyi kendilerinin dışındaki faktörlere yapma davranışlarının arttığ söylenebilir.

Akademik ortamlarda olumsuz değerlendirilme korkusunu yordayan değişkenlerden sonuncusu ise mükemmeliyetçilik değişkeni olmuştur. Alanyazın incelendiğinde uyumsuz mükemmeliyetçilikle bireylerin olumsuz değerlendirilme korkuları arasında pozitif yönlü, istatistiksel olarak anlamlı düzeyde ilişki olduğunu gösteren çalışmalar yer almaktadır (Shafique, Gul ve Raseed, 2017; Şimşek, 2018). Satıc1, Göcet-Tekin ve Deniz (2020) yapmış oldukları çalışmada, üniversite öğrencilerinin akademik mükemmelliyetçilikleri ile olumsuz değerlendirilme korkuları arasında orta düzeyde pozitif yönlü anlamlı bir ilişki bulmuşlardır. Akgül ve Nuhoğlu (2020) tarafından yapılan araştırmada üstün yetenekli öğrencilerin uyumsuz mükemmeliyetçiliklerinden olan hatalara duyarlıklarının matematik kaygılarını pozitif yönde, anlamlı şekilde yordadığını bulmuşlardır. Akademik başarıya ilişkin bilişsel çarpıtmalardan olan mükemmeliyetçilik başarıya dair katı ve yüksek beklentiler olarak tanımlanmıştır (Kaya, 2018). Pacht'in (1984) mükemmelliyetçi öğrencilere ilişkin sıraladığı özelliklerden bazıları, bu öğrencilerin kendilerini başarıdan ziyade başarısızlık korkusu ile motive etmeleri ve doğru cevaptan emin olmadıkça sorulara yanıt vermeye gönüllü olma isteksizlikleridir. Elde edilen sonuç ve alanyazın dikkate alındığında, lise öğrencilerin akademik ortamlarda hata yaparlarsa küçük duruma düşme veya başarısızlıkla etiketlenme 
gibi düşünce yapılarına sahip olmaları, akademik ortamlarda olumsuz değerlendirilme korkularını arttırabilir.

$\mathrm{Bu}$ araştırma kapsamında akademik ortamlarda olumsuz değerlendirilme korkusunun akademik başarıya ilişkin bilişsel çarpıtmalar bağlamında inceleme yapılmış ve bilişsel çarpıtmaların anlamlı düzeyde rolü olduğu bulunmuştur. Bundan sonraki çalışmalarda, hem akademik ortamlarda olumsuz değerlendirilme korkusu değişkeniyle hem de akademik başarıya ilişkin bilişsel çarpıtmalar değişkeniyle ilgili çalışma sayısı arttırılabilir. Akademik ortamlarda olumsuz değerlendirilme korkusu akademik özyeterlik, akademik başarı, kişilik özellikleri, akademik benlik saygısı gibi bireysel değişkenlerin yanısıra aile, arkadaş, öğretmen gibi sosyal çevre değişkenleriyle çalışılabilir. Ayrıca farklı öğrenim kademelerinde de benzer çalışmalar yapılabilir. Akademik ortamlarda olumsuz değerlendirilme korkusu olan öğrencilere bilişsel davranışçı yaklaşıma dayalı bireysel veya grupla psikolojik danışma hizmetleri verilebilir. Bu konuda öğrencilerde farkındalık oluşturacak broşürler asılabilir veya grup rehberliği boyutunda bilgilendirme toplantıları yapılabilir. 


\section{Kaynakça}

Akgül, S., \& Nuhoğlu, H. (2020). Üstün yetenekli öğrencilerin matematik kaygısı ve mükemmeliyetçilik düzeylerinin incelenmesi. Yaşadıkça Eğitim, 34(2), 299-312. https://doi.org/10.33308/26674874.2020342204.

Alkan, V. (2015). Akademik ortamlarda olumsuz değerlendirilme korkusu ölçeğinin geliştirilmesi. (Yayımlanmamış yüksek lisans tezi). Ankara Üniversitesi Eğitim Bilimleri Enstitüsü, Ankara.

Atasoy, M., Karabulut, E. O., \& Var, L.(2018). The research on the negative evaluation anxiety of taekwondo players by different variables. Turkish Journal of Sport and Exercise, 20(3), 158-162. https://doi.org/10.15314/tsed.466880.

Bahadır, F. (2020). University students' perceptions of the reasons for success and failure: A qualitative study. Journal of Educational Issues, 6,2, 214-231. https://doi.org/10.5296/jei.v6i2.17560.

Bıçak, S. (2019). Repeat level preparatory school students' causal dimensionality and their causal attributions to perceived success and failure. (Unpublished Master Thesis). Middle East Technical Unıversity, Social Sciences Instıtute, Ankara.

Bridges, K. R., \& Harnish, R. J. (2010). Role of irrational beliefs in depression and anxiety: A review. Health, 2(08), 862-877. doi:10.4236/health.2010.28130.

Brundage, S. B., Winters, K. L., \& Beilby, J. M. (2017). Fear of negative evaluation, trait anxiety, and judgment bias in adults who stutter. American journal of speech-language pathology, 26(2), 498-510. https://doi.org/10.1044/2017 AJSLP-16-0129.

Büyüköztürk, Ş. (2010). Sosyal bilimler için veri analizi el kitabı (11. Basım). Ankara: Pegem Akademi Yayıncilik.

Büyüköztürk, S., Kılıç Çakmak, E., Akgün, O.E., Karadeniz, S., \& Demirel, F. (2012). Bilimsel Araştırma Yöntemleri. Ankara: Pegem Akademi.

Carleton, R. N., Collimore, K. C., \& Asmundson, G. J. G. (2007). Social anxiety and fear of negative evaluation: Construct validity of the BFNE-II. Journal of Anxiety Disorders, 21(1), 131-141. doi:https://doi.org/10.1016/j.janxdis.2006.03.010.

Chan, S. M., Chan, S. K., \& Kwok, W. W. (2015). Ruminative and catastrophizing cognitive styles mediate the association between daily hassles and high anxiety in Hong Kong adolescents. Child Psychiatry \& Human Development, 46(1), 57-66. https://doi.org/10.1007/s10578-014-0451-9.

Cheng, G., Zhang, D., \& Ding, F. (2015). Self-esteem and fear of negative evaluation as mediators between family socioeconomic status and social anxiety in Chinese emerging adults. Int J Soc Psychiatry, 61(6), 569-576. doi:10.1177/0020764014565405.

Cook, S.I., Meyer, D., \& Knowles, S. R. (2019). Relationships between psychoevolutionary fear of evaluation, cognitive distortions, and social anxiety symptoms: A preliminary structural equation model. Australian Journal of Psychology, 71(2), 92-99. https://doi.org/10.1111/ajpy.12215.

Çarkıt, E. (2016). Üniversite öğrencilerinin düşünce hatalar ve duyguları ifade etmelerinin mükemmelliyetçilik tutumların yordaması. (Yayımlanmamış yüksek lisans tezi). Necmettin Erbakan Üniversitesi Eğitim Bilimleri Enstitüsü, Konya.

Çelik, Ç.B., \& Odaci, H. (2015). Akademik erteleme davranışının bazı kişisel ve psikolojik değişkenlere göre açiklanması. Hacettepe Üniversitesi Eğitim Fakültesi Dergisi, 30(3), 31-47. 
Çelik, Y., \& Atilla, G. (2019). Üniversite öğrencilerinde kendini sabotaj, olumsuz değerlendirilme korkusu ve benlik saygisi. Kahramanmaraş Sütçü İmam Üniversitesi İktisadi ve İdari Bilimler Fakültesi Dergisi, 9(2), 177-198.

Çetin, B., Doğan, T., \& Sapmaz, F. (2010). Olumsuz değerlendirilme korkusu ölçeği kısa formu'nun Türkçe uyarlaması: Geçerlik ve güvenirlik çalışması. Ĕ̆itim ve Bilim, 35(156), 205-216.

Çetin, B., İlhan, M., \& Yılmaz, F. (2014). Olumsuz değerlendirilme korkusu ve akademik risk alma arasındaki ilişkinin kanonik korelasyonla incelenmesi. Kuram ve Uygulamada Eğitim Bilimleri, 14(1), 135-158.

Deffenbacher, J. L., Zwemer, W. A., Whisman, M. A., Hill, R. A., \& Sloan, R. D. (1986). Irrational beliefs and anxiety. Cognitive Therapy and Research, 10(3), 281291. https://doi.org/10.1007/BF01173466.

Downing, V. R., Cooper, K. M., Cala, J. M., Gin, L. E., \& Brownell, S. E. (2020). Fear of negative evaluation and student anxiety in community college active-learning science courses. CBE-Life Sciences Education, 19:ar20, 1-16. DOI: 10.1187/cbe.19-09-0186.

Dozois, D. J. A., \& Beck, A. T. (2008). Cognitive schemas, beliefs and assumptions. In K. S. Dobson \& D. J. A. Dozois (Eds.), Risk factors in depression (pp. 121-143). Oxford, United Kingdom: Elsevier/Academic Press

Duke, D., Krishnan, M., Faith, M., \& Storch, E. A. (2006). The psychometric properties of the Brief Fear of Negative Evaluation Scale. J Anxiety Disord, 20(6), 807-817. doi:10.1016/j.janxdis.2005.11.002.

Duran, S., Karadaş, A., \& Kaynak, S. (2017). Hemşirelik öğrencilerinin olumsuz otomatik düşünceleri ve akademik başarıları arasındaki ilişki. Kocaeli Tıp Dergisi, 6(2), 30-37.

Field, A. (2005). Discovering statistics using SPSS. Thousand Oaks, CA, US.

İlhan, M., \& Güler, N. (2018). Likert tipi ölçeklerde rasch modelinin kullanımı: olumsuz değerlendirilme korkusu ölçeği-öğrenci formu (ODKÖ-ÖF) üzerinde bir uygulama. Trakya Üniversitesi Ĕ̆itim Fakültesi Dergisi, 8(4), 756-775. Doi: 10.24315/trkefd.357367

Kanbur, E. (2018). Çalışanların olumsuz değerlendirilme korkusunun örgütsel sessizlik üzerine etkisi. İşletme Araştırmaları Dergisi, 10(1), 382-402. DOI: 10.20491/isarder.2018.386.

Kaya, İ. (2018). Akademik başarıya ilişkin bilişsel çarpıtmalar ölçeğinin (ABIBÇÖ) geliştirilmesi. Mersin University Journal of the Faculty of Education, 14(3), 1082-1098. DOI: $\underline{10.17860 / \text { mersinefd.435605. }}$

Khan, S. R., \& Naqvi, I. (2016). Self-criticism and fear of negative evaluation among university students with and without obesity. Pakistan Journal of Psychological Research, 31(2), 509-530.

Khanam, S. J., \& Moghal, F. (2012). Self esteem as a predictor of fear of negative evaluation and social anxiety. Pakistan Journal of Psychology, 43(1), 91-100.

Kızgın, Y., \& Dalgın, T. (2012). Atfetme teorisi: Öğrencilerin başarı ve başarısızlıklarını değerlendirmedeki atfetme farklılıkları. Uluslararası Yönetim İktisat ve İşletme Dergisi, 8(15), 6177.

Knights JA \& Kennedy BJ (2007) Medical school selection: impact of dysfunctional tendencies on academic performance. Med Educ. 41(4):362-8. DOI: 10.1111/j.1365-2929.2007.02707.x 
Kocovski, N. L., \& Endler, N. S. (2000). Social anxiety, self-regulation, and fear of negative evaluation. European Journal of Personality, 14(4), 347-358. doi:10.1002/10990984(200007/08)14:4<347::AID-PER381>3.0.CO;2-7

Koydemir-Özden, S., \& Demir, A. (2009). The Relationship between perceived parental attitudes and shyness among Turkish youth: Fear of negative evaluation and self-esteem as mediators. Current Psychology, 28(3), 169-180. doi:10.1007/s12144-009-9054-1

Köse, E., Bayköse, N., Turan, E. B., \& Lapa, T. Y. (2016). Düzenli egzersiz yapan bireylerde olumsuz değerlendirilme korkusunun vücut algılarını belirlemedeki rolü. Mediterranean Journal of Humanities, VI/2, 351-360. https://doi.org/10.13114/MJH.2016.303.

Kuru, E., Safak, Y., Özdemir, İ., Tulacı, R. G., Özdel, K., Özkula, N. G., \& Örsel, S. (2018). Cognitive distortions in patients with social anxiety disorder: Comparison of a clinical group and healthy controls. The European Journal of Psychiatry, 32(2), 97-104.DOI: 10.1016/j.ejpsy.2017.08.004.

Leary, M. R. (1983). A brief version of the Fear of Negative Evaluation Scale. Personality and Social Psychology Bulletin, 9(3), 371-375. https://doi.org/10.1177/0146167283093007.

Nonterah, C. W., Hahn, N. C., Utsey, S. O., Hook, J. N., Abrams, J. A., Hubbard, R. R., \& OpareHenako, A. (2015). Fear of negative evaluation as a mediator of the relation between academic stress, anxiety and depression in a sample of Ghanaian college students. Psychology and Developing Societies, 27(1), 125-142. doi:10.1177/0971333614564747.

Ömür, Y. E., Aydin, R., \& Argon, T. (2014). Olumsuz değerlendirilme korkusu ve akademik sahtekârlık. Eğitim ve İnsani Bilimler Dergisi: Teori ve Uygulama, 5 (9), 131-149.

Özgüngör, S. (2006). Öz bilinç, olumsuz değerlendirilme korkusu, performans odakli sinif algisi ve not yönelimi. Pamukkale Üniversitesi Eğitim Fakültesi Dergisi, 19(19), 85-92.

Pacht, A. R. (1984). Reflections on perfectionism. American Psychologist, 39, 386-390. https://doi.org/10.1037/0003-066X.39.4.386.

Pereira, A. I. F., Barros, L., \& Mendonça, D. (2012). Cognitive errors and anxiety in school aged children. Psicologia: Reflexão e Crítica, 25(4), 817-823. http://dx.doi.org/10.1590/S010279722012000400022 .

Pitarch, M. J. (2010). Brief version of the fear of negative evaluation scale - Straightforward Items (BFNE-S): psychometric properties in a Spanish population. Span J Psychol, 13(2), 981-989. DOI: $10.1017 / \mathrm{s} 1138741600002626$.

Reichenberger, J., Smyth, J. M., \& Blechert, J. (2018). Fear of evaluation unpacked: day-to-day correlates of fear of negative and positive evaluation. Anxiety, Stress, \& Coping, 31(2), 159-174. doi:10.1080/10615806.2017.1396826.

Satici, B., Göcet-Tekin, E., \& Deniz, M. E. (2020). Cognitive flexibility and mental well-being: fear of negative evaluation and academic perfectionism as serial mediators. Erzincan Üniversitesi Ĕ̆itim Fakültesi Dergisi, 22(2), 386-396. https://doi.org/10.17556/erziefd.632776.

Shafique, N., Gul, S., \& Raseed, S. (2017). Perfectionism and perceived stress: The role of fear of negative evaluation. International Journal of Mental Health,46(4), 312-326. https://doi.org/10.1080/00207411.2017.1345046.

Şimsek, M. (2018). Lise öğrencilerinin akademik erteleme davranişlari ile mükemmeliyetçilik ve olumsuz değerlendirilme korkusu arasindaki ilişkilerde benlik saygisinin aracı rolü. (Yayımlanmamış Yüksek Lisans Tezi). Mersin Üniversitesi, Eğitim Bilimleri Enstitüsü, Mersin. 
Talhat, K., \& Aslam, N. (2012). Fear of negative evaluation and psychological distress among patients of drug addiction. Journal of the Indian Academy of Applied Psychology, 38(3), 44-54.

Utschig, A. C., Presnell, K., Madeley, M. C., \& Smits, J. A. J. (2010). An investigation of the relationship between fear of negative evaluation and bulimic psychopathology. Eating Behaviors, 11(4), 231-238. doi:https://doi.org/10.1016/j.eatbeh.2010.05.003

Weeks, J. W., Heimberg, R. G., \& Rodebaugh, T. L. (2008). The Fear of positive evaluation scale: Assessing a proposed cognitive component of social anxiety. Journal of Anxiety Disorders, 22(1), 44-55. doi:https://doi.org/10.1016/j.janxdis.2007.08.002

Weems, C. F., Berman, S. L., Silverman, W. K., \& Saavedra, L. M. (2001). Cognitive errors in youth with anxiety disorders: The linkages between negative cognitive errors and anxious symptoms. Cognitive Therapy and Research, 25(5), 559575. https://doi.org/10.1023/A:1005505531527.

Williams, K. C., Falkum, E., \& Martinsen, E. W. (2015). Fear of negative evaluation, avoidance and mental distress among hearing-impaired employees. Rehabilitation psychology,60(1), 51. DOI: $10.1037 /$ rep0000028 